\title{
MEDIA KOMIK PADA PELAJARAN IPA UNTUK MENINGKATKAN MULTIPLE INTELLIGENCES SISWA SD
}

\author{
Margaretha Sri Yuliariatiningsih*)
}

\begin{abstract}
This study was grounded on the students' hobby in reading comics. The result of the literature study showed that comic used as media in learning Physics was very effective as learning media and attractive to be read. One of the supporting factors of this success in improving the students' multiple intelligences was the integration of art and craft activities in the science learning process. Moreover, the theory of multiple intelligences accomodated students with various way of learning thinking.

The developed training model in this study consisted of five stages that were orientation, presentation, structured excersice, guided excersice and individual excersice. In each Science class, the learning process was always started with the elicitation of students' prior knowledge. Then each student got one comic to be read. After the reading session, the teacher asked them about the contents of the comics either classically or individually. In the next step the students were invited to observe the demonstration done by the teacher only if the instruments or materials were not safe for them, (e.g hot water). Nevertheless, if they were safe enough for the students, they were allowed to do the experiment by themselves. Students' worksheets (LKS) were done by the students in group to develop their interpersonal and verbal-linguistic intelligences.

Based on observation during experiments and drawing activities, the students' visual-spatial intelligences were developed. Every learning process was always ended with knowledge test individually which would be discussed later. The study concluded that: 1) the training model improved PGSD students' skills in developing comic as teaching media, 2) comics are proven to improve the elementary school students' motivation in learning science, 3) comic enhanced elementary school students' understanding in science knowledge which was indicated by the achievement of the students' test score (85 point grade). Comic also developed elementary school students' multiple intelligences in the aspects of verbal-linguistic, logical-mathematic, visual-spatial, naturalist, and interpersonal. It is recommended that comic should be developed as teaching media especially in elementary school. Comis can be used as one alternative of learning medias that can motivate students to learn something as well as improving their reading hobby.
\end{abstract}

\section{Key Word: comic, motivation, learning science, achievement}

\section{A. Latar Belakang Masalah}

UU Sisdiknas No. 20/2003 pasal 6 tentang kerangka dasar dan struktur kurikulum, dijelaskan bahwa setiap kelompok mata pelajaran dilaksanakan secara holistik sehingga mempengaruhi pemahaman dan/atau penghayatan peserta didik. Pada pasal 19 tentang standar proses dan panduan penyusunan KTSP (BSNP, 2006) juga mengamanatkan bahwa proses pembelajaran pada satuan pendidikan 
diselenggarakan secara interaktif, inspiratif, menyenangkan, menantang, memotivasi peserta didik untuk berpartisipasi aktif, serta memberikan ruang yang cukup bagi prakarsa, kreativitas, dan kemandirian sesuai dengan minat, bakat, dan perkembangan fisik serta psikologis peserta didik.

Project Summit (2000) menemukan bahwa salah satu faktor yang mendukung keberhasilan untuk meningkatkan multiple intelligences siswa adalah dengan memasukkan unsur seni ke dalam proses pembelajaran baik secara terfragmentasi maupun secara terpadu lintas mata pelajaran.

Yanthi,N, (2009:70) mengemukakan bahwa pelajaran IPA yang dibelajarkan secara dwibahasa pada konsep mengenal bagian-bagian tubuh hewan dengan metode bercerita menggunakan media wayang dapat meningkatkan multiple intelligences siswa pada aspek kecerdasan naturalis, logika matematis, linguistik, visual spasial, dan interpersonal.

Hasil wawancara menunjukkan ketertarikan siswa SD pada komik sangat tinggi seperti Avatar dan Naruto, termasuk tontonan film di televisi seperti Sponge Bob, Tin Tin dan Naruto. Untuk mencapai tujuan pembelajaran, memotivasi belajar dan meningkatkan multiple intelligences siswa SD, maka dikembangkan media komik dalam pembelajaran IPA sesuai dengan karakter siswa SD.

Berdasarkan latar belakang di atas, tujuan penelitian ini adalah :

a. meningkatkan keterampilan guru dalam mengembangkan media komik ,

b. meningkatkan motivasi belajar IPA siswa SD melalui media komik,

c. meningkatkan pemahaman siswa SD pada pembelajaran IPA melalui media komik,

d. mengembangkan multiple intelligences siswa SD melalui media komik.

\section{B. Kajian Pustaka}

Mengajar dapat diartikan memperlihatkan sesuatu kepada seseorang melalui tanda atau simbol, untuk membangkitkan atau menumbuhkan respon (Sanjaya,W.2007:208). Menurut Smith mengajar adalah suatu proses menanamkan ilmu pengetahuan atau keterampilan (Sanjaya,W,2007:94). Namun menurut KTSP 2006, mengajar bukan sekedar menyampaikan materi pelajaran, tetapi juga sebagi proses mengatur lingkungan belajar. Jadi belajar adalah suatu proses aktivitas mental seseorang dalam berinteraksi dengan lingkungannya sehingga menghasilkan perubahan tingkah laku yang bersifat positif baik perubahan dalam aspek pengetahuan, sikap, maupun psikomotorik

Ilmu pengetahuan Alam (IPA) merupakan cabang ilmu pengetahuan yang mempelajari tentang alam sekitar dan berbagai gejalanya. Conant (Sumaji,et al.1998:31) menyatakan bahwa IPA adalah suatu deretan konsep serta skema konseptual yang berhubungan satu sama lain, dan yang tumbuh sebagai hasil eksperimentasi dan observasi, serta berguna untuk diamati dan dieksperimentasikan lebih lanjut.

Pembelajaran IPA di SD dibelajarkan oleh guru dengan menyederhanakan ide dan proses, menyesuaikan dengan minat dan kebutuhan siswa, serta mempertimbangkan kemampuan fisik dan kognitif siswa. Guru berperan sebagai fasilitator pembelajaran, sedangkan siswa aktif mengkonstruksi pengetahuan. 
Agar terjadi proses belajar, maka pada pembelajaran IPA, siswa dilibatkan dengan memanipulasi benda konkrit dan dirancang agar terjadi interaksi sosial, sehingga berkembang keterampilan ilmiahnya (Gega, P,C,1982:8).

Siswa SD belajar dengan baik jika dihadapkan pada permasalahan faktual yang bebeda-beda. Melalui belajar penemuan siswa akan lebih memahami konsep-konsep IPA yang tertanam dalam struktur kognitifnya dan dapat menggunakannya untuk memecahkan masalah baru.

Ausubel, Bruner, Gagne (Gega,P,C. 1982 :25) berpendapat dalam membelajarkan siswa SD perlu melibatkan aktivitas indera atau simulasi dengan anggota tubuh dan benda nyata (hands-on), dan bukan hanya proses berpikir semata (minds-on). Jadi proses berpikir siswa SD akan lebih baik bila didahului dengan mengota-atik objek nyata dengan menggunakan indra.

Secara umum komik sering disebut sebagai cerita bergambar. Stuart Mc Cloud (2001) berpendapat bahwa komik adalah susunan gambar-gambar yang terkelompokkan dan terpola dalam urutan tertentu sehingga dapat menyampaikan pesan kepada pembacanya. Komik sebagai media gambar diam akan memunculkan efek maksimal pada segi pengenalan visual siswa.

Pengolahan objek visual yang dilakukan dalam komik sering bersifat menghibur dengan adanya rangkaian teks penjelas, sehingga informasi yang disampaikan melalui ceritanya lebih mudah untuk dimengerti dibandingkan beberapa karya seni rupa lainnya seperti gambar atau lukisan. Melalui alur cerita yang panjang pada komik, dapat menarik perhatian siswa untuk membacanya. Komik juga dapat melibatkan siswa secara emosional sehingga akan terus membacanya hingga selesai, terutama jika cerita yang terdapat pada komik memiliki kedekatan tema dengan keseharian siswa. Dengan bantuan alur cerita, diharapkan tujuan atau pesan penulis dapat dicapai dengan baik.

Kecenderungan dalam belajar IPA di SD adalah banyaknya buku teks SD yang setiap halamannya lebih didominasi oleh tulisan daripada gambar sehingga kurang membangkitkan ketertarikan siswa untuk membaca. Sebagai media pembelajaran IPA, komik dapat menyampaikan pesan berupa konsep-konsep IPA dengan lebih jelas dan menarik dibandingkan media gambar tanpa cerita. Pesan yang disampaikan melalui komik dapat lebih jelas, menarik, dan mudah dipahami dalam susunan rangkaian cerita yang dibawanya.

Gardner,H,E, menemukan ada delapan aspek multiple intelligences, yaitu : kecerdasan linguistik, kecerdasan logika matematis, kecerdasan musikal, kecerdasan kinestika, kecerdasan interpersonal, kecerdasan intrapersonal, dan kecerdasan naturalis(http:/.www.infed.org/thinkers/gardner.htm, 2008).

Hasil penelitian Project Summit (2000) memperkuat temuan penelitian bahwa salah satu faktor yang mendukung keberhasilan peningkatan multiple intelligences siswa adalah dengan memasukkan unsur seni ke dalam proses pembelajaran baik secara fragmentasi maupun secara terpadu lintas mata pelajaran. Selain itu Kornhaber (http:/.www.infed.org/thinkers/gardner.htm, 2008) menyatakan teori multiple intelligences mengakomodasikan siswa dengan beragam cara berpikir dan belajar. 


\section{Metode Penelitian}

Penelitian ini mengkaji serta mempelajari secara kolaboratif suatu implementasi pembelajaran terhadap aktivitas guru dan siswa kelas $\mathrm{V}$ dan kelas IV SD. Metode penelitian yang digunakan menekankan pada suatu kajian yang berawal dari situasi alamiah di lapangan. Rancangan penelitian yang dipilih adalah rancangan kualitatif naturalistik yang disusun berdasarkan prinsip latar situasi dan kondisi lapangan. Oleh karena itu dalam penelitian ini melibatkan langsung guru dan siswa SD dalam proses kegiatan pembelajaran di SD.

Subjek penelitian ini adalah guru kelas IV SD Laboratorium UPI Kampus Cibiru UPI beserta siswanya yang berjumlah 26 dan guru SDN Karanglayung Tanjungsari kelas V beserta siswanya sebanyak 26 . Adapun objek penelitian adalah keterampilan guru dalam mengembangkan cerita dan komik.

Penyusunan instrumen pada penelitian ini bertujuan mendapatkan data untuk dideskripsikan berupa lembar kerja siswa digunakan untuk menilai kinerja siswa selama melakukan kegiatan eksplorasi dalam pembelajaran IPA dan untuk mengetahui pemahaman siswa terhadap isi komik yang dibacanya. Lembar tes digunakan untuk melihat pemahaman siswa terhadap konsep yang dibelajarkan. Lembar observasi supervisi klinis untuk mengungkapkan aktivitas guru sedangkan lembar observasi terstruktur untuk mengungkapkan aktivitas, keterampilan dan jenis multiple intelligences siswa yang muncul saat pembelajaran berlangsung. Catatan lapangan untuk merekam kejadian penting, serta lembar wawancara untuk mendata kesan guru dan siswa SD terhadap pelaksanaan pembelajaran IPA dengan media komik.

Instrumen tersebut di atas digunakan untuk menjaring data kualitatif melalui penafsiran secara langsung atau dianalisis deskriptif terhadap fenomena yang ada.

\section{Hasil Penelitian dan Pembahasan}

Pada tahap perencanaan guru akan mengembangkan media pembelajaran komik dalam pembelajaran IPA . Pada tahap pendekatan orientasi dipilih pendekatan konstruktivis dan Problem Based Learning (PBL) karena diasumsikan dapat meningkatkan motivasi belajar siswa SD. Melalui pendekatan ini siswa akan dikembangkan keterampilannya dalam memecahkan permasalahan dalam kehidupan sehari-hari berdasarkan fenomena-fenomena faktual yang diperoleh siswa melalui pengalaman dan kegiatan belajar. Media komik ini kemudian akan digunakan oleh guru dalam pembelajaran IPA di SD dan melihat pengaruhnya terhadap peningkatan motivasi belajar, pemahaman siswa terhadap materi pembelajaran, dan aspek perkembangan multiple intelligences siswa SD.

Pada tahap presentasi dan simulasi diputuskan untuk menggunakan siswa sebagai karakter tokoh dalam cerita yang akan menjadi subjek penelitian di SDN Karanglayung pada kosep pesawat sederhana. Di SD Laboratorium UPI Kampus Cibiru siswa kelas IV C yang digunakan sebagai subjek penelitian, karena 90\% siswanya senang membaca komik sedangkan konsep Perubahan Lingkungan Fisik Daratan dijadikan objek belajar sesuai dengan kalender akademik di sekolah tersebut. Sub konsep yang dirancang dalam cerita adalah banjir, erosi, abrasi, dan korasi. 
Komik yang dirancang oleh guru mendapat sambutan yang sangat baik dari siswa oleh siswa SDN Karanglayung. Dalam setiap pertemuan siswa antusias membaca karena tokoh-tokoh yang ada dalam komik adalah siswa itu sendiri. Setiap siswa diberi kesempatan yang sama sebagai tokoh dalam komik pada setiap tindakan, walau ada seorang siswa yang keberatan dengan penggambaran tubuhnya di dalam komik tersebut.

Perhatian siswa sebagian besar terfokus pada komik. Siswa masih terlihat asyik membaca komik bahkan saat guru sedang mendemonstrasikan percobaan tentang pesawat sederhana. Guru mampu menjalin komunikasi yang baik melalui penggunaaan media belajar berupa komik. Guru juga memberikan motif belajar berupa reinforcement positif, pada siswa yang mau dan dapat menjawab pertanyaan. Data yang dihimpun adalah perolehan nilai evaluasi akhir sebagai representasi dari pemahaman siswa terhadap materi pelajaran, dan data hasil observasi terhadap peningkatan motivasi belajar siswa.

Nilai evaluasi akhir tiap tindakan dan nilai rata-rata setiap siklus dapat dilihat pada gambar di halaman berikut.

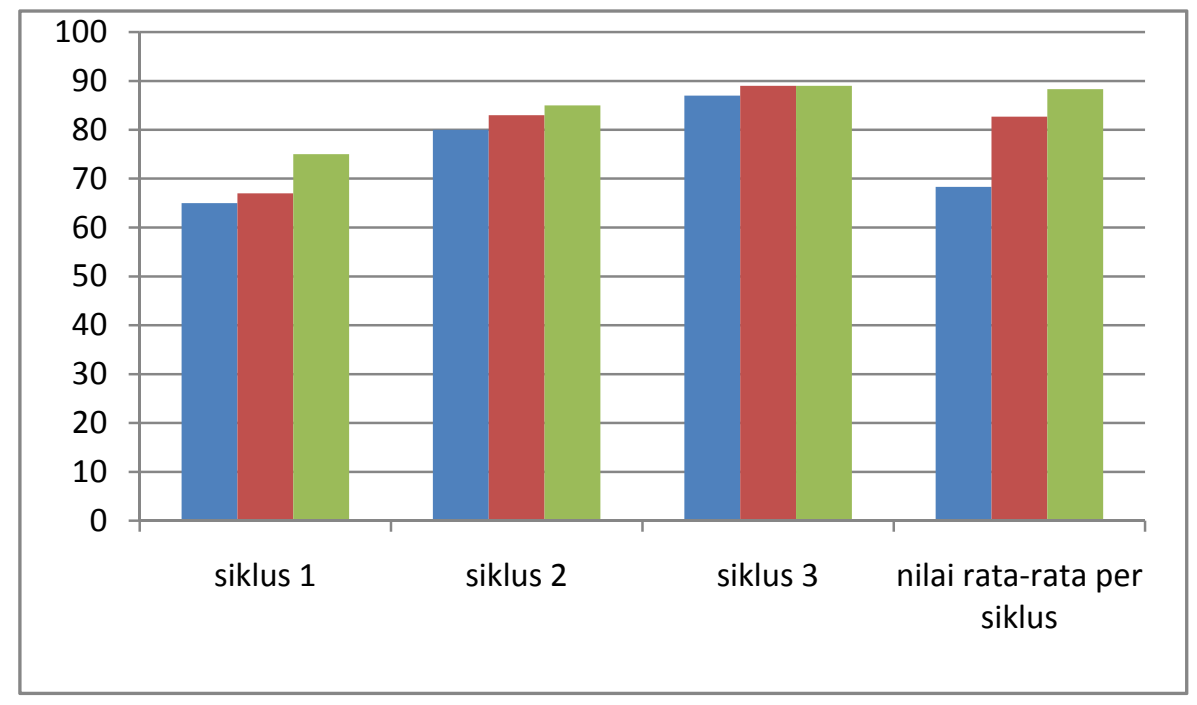

Pembelajaran yang dilakukan oleh guru di SD Laboratorium UPI Kampus Cibiru adalah tentang pencegahan perubahan lingkungan fisik daratan. Siswa diajak menemukan solusi pencegahan perubahan lingkungan fisik daratan dalam LKS maupun dalam evaluasi.

Waktu yang digunakan pada kegiatan awal tindakan 1 dan 2 lebih lama dari rencana yang tercantum dalam rencana permbelajaraan. Hal ini mengakibatkan waktu untuk pelaksanaan kegiatan inti menjadi tereduksi. Siswa melakukan kegiatan diskusi dan eksplorasi dengan tergesa-gesa.

Ketidaefisienan penggunaan waktu juga tampak pada saat guru meminta beberapa siswa untuk menceritakan kembali isi komik yang telah dibaca di depan kelas. Siswa yang lain terlihat jenuh mendengar cerita temannya sehingga tidak menghiraukan teman yang sedang bercerita tetapi asyik dengan kegiatan masingmasing. Rata-rata siswa dapat menceritakan kembali isi komik dengan bahasa 
yang berbeda tetapi tidak mengurangi makna yang terkandung dalam komik tersebut.

Kegiatan inti berupa kegiatan menggambar secara berkelompok (tindakan 1) dan percobaan (tindakan 2), serta kegiatan mengisi lembar kerja siswa dengan cara berdiskusi membuat siswa merasa senang. Gambar diselesaikan pada pertemuan terakhir. Dikarenakan waktu yang digunakan terbatas sehingga tidak ada kesimpulan yang bisa diambil dari hasil kegiatan.

Kerjasama yang terjalin dalam kegiatan kelompok umumnya sudah baik, hanya ada 4 siswa yang kurang dapat bekerja sama dengan anggota kelompok lainnya. Para siswa tersebut umumnya kurang senang diatur oleh orang lain.

Pada tindakan 3 diskusi yang terjadi di dalam kelompok semakin baik, dan setiap anggota kelompok berusaha memberikan ide saat kegiatan membuat poster. Pembelajaran terlihat hidup dan menyenangkan karena guru meminta perwakilan dari setiap kelompok untuk berkampanye tentang pentingnya menjaga lingkungan untuk mengurangi bencana alam melalui simulasi kampanye calon presiden.

Guru dan tim melakukan penilaian terhadap motivasi belajar, multiple intelligences, dan pemahaman siswa, yang tampak pada gambar di bawah.

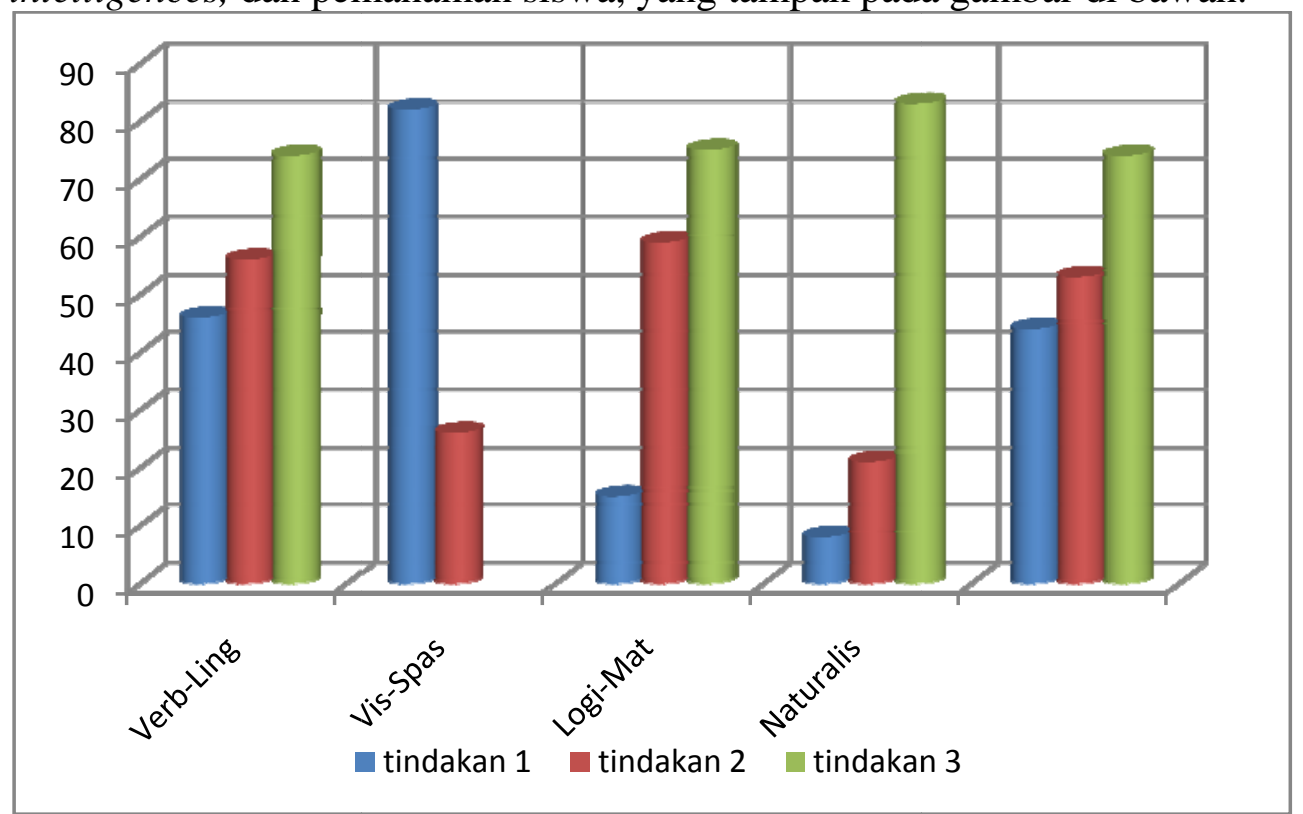

\section{Pemunculan aspek Multiple Intelligences Siswa SD Laboratorium UPI Kampus Cibiru}

Guru menunjukkan kreativitas dalam merancang cerita dan mengembangkan komik yang berhubungan dengan konsep IPA di SD. Membutuhkan waktu dua hari untuk merancang komik dalam setiap pertemuan. Kendala yang ditemui adalah salah seorang guru memiliki keterbatasan dalam menuangkan cerita ke dalam bentuk komik.

Indah merupakan anggota penelitian yang memiliki bakat menggambar, sehingga mampu menuangkan idenya ke dalam bentuk visualisasi gambar dua 
dimensi. Walaupun demikian perlu dipertimbangkan tentang penampilan gambar seorang siswa, karena anak-anak ingin sama dengan anak yang lainnya dan kurang senang bila menjadi bahan tertawaan.

Untuk mengatasi kurang terampilnya dalam menggambar komik dalam pengembangan media pembelajaran, seorang guru dituntut kreatif dalam mencari sumber belajar lainnya, misalnya dari internet, dari komik, majalah anak-anak, buku teks atau koran. Kreativitas ini merupakan satu dari banyak aspek kompetensi yang harus dimiliki guru ( Hammond,L,D, 2006 ; Abidin,Y, 2009:9). Hal lainnya yang harus dipertimbangkan guru adalah menarik, up to date, mudah dicari, murah harganya, sesuai dengan karakteristik siswa SD dengan cerita yang sederhana tetapi mudah dipahami oleh anak, serta mengembangkan keterampilan yang dubutuhkan siswa ( Tanner,R \& Green,C, 1998). Menurut Hamond, melalui pemodelan pelatihan diharapkan dihasilkan para adaptive expert, yaitu guru ahli yang mampu mengembangkan pengetahuan dan kompetensinya agar dapat menjawab kebutuhan tantangan zaman yang terus berkembang (Yuliariatiningsih, M,S, 2008).

Penggunaan komik dalam pembelajaran terbukti dapat membantu siswa mengembangkan hobi membaca dalam memahami pembelajaran seperti hasil wawancara. Hal relevan dikemukakan oleh Pranata,M, (2003), bahwa seseorang akan belajar dengan lebih maksimal jika berinteraksi dengan stimulus yang sesuai dengan gaya belajarnya. Pesan yang disampaikan oleh komik dianggap jelas, menarik, dan mudah dipahami.

Hal lain yang menjadikan siswa tertarik pada komik adalah cerita yang berhubungan dengan kejadian-kejadian yang relevan dengan kehidupan seharihari. Hal ini sesuai dengan pendapat Megawangi bahwa pembelajaran memerlukan partisipasi aktif para siswa. Motivasi belajar muncul karena siswa mempraktikkan hal-hal konkret, bermakna dan relevan dalam kehidupannya (Nugraha,I,S,E, 2009:87).

Pada tindakan 2, nilai tes akhir siswa SD Laboratorium mengalami penurunan, karena beberapa siswa menjawab berdasarkan pemahamannya bukan berdasarkan perintah yang terdapat pada persoalan. Di lain sisi, kekurangpahaman siswa terhadap perintah soal dapat diakibatkan oleh kekurangtelitian siswa atau kurang jelasnya instruksi yang diberikan. Bradshaw (2005) menyatakan bahwa dalam memberikan instruksi kepada anak, harus memerhatikan empat prinsip, yaitu 4 C (complete, concise, clear, checked).

Aspek multiple intelligences yang terekam dalam penelitian ini adalah verbal- linguistik, visual-spasial, logika- matematis, naturalis,dan interpersonal. Ada keterkaitan antara beberapa aspek multiple intelligences. Bahkan menurut Tanner,R, (2001 : 40 ) dapat terjadi overlap beberapa aspek multiple intelligences dalam satu jenis kegiatan. Misalnya, pada kegiatan membaca komik dan menceritakan kembali isinya, dapat berkembang multiple intelligences pada aspek verbal linguistik, logika matematis, dan visual spasial. Selain itu pengembangan satu jenis multiple intelligences dapat dilakukan dengan memvariasikan atau mengintegrasikan beberapa kegiatan belajar. 


\section{E. Kesimpulan dan Saran}

berikut.

Kesimpulan yang dapat diambil dari hasil penelitian ini adalah sebagai

1. Model pelatihan dapat meningkatkan dan mengembangkan keterampilan mahasiswa dalam merancang media pembelajaran berupa komik pada mata pelajaran IPA di SD.

2. Motivasi belajar IPA pada siswa SD meningkat dengan digunakannya media pembelajaran IPA berupa komik.

3. Media komik dapat meningkatkan pemahaman siswa terhadap materi pelajaran IPA pada konsep pesawat sederhana dan perubahan lingkungan fisik daratan hal ini tampak pada kenaikan nilai tes akhir pada setiap siklus pembelajaran.

4. Media komik dapat meningkatkan multiple intelligences siswa SD pada aspek verbal-linguistik, visual-spasial, logika-matematis, dan interpersonal.

Saran untuk para peneliti yang akan mengembangkan media komik adalah sebagai berikut.

1. Peningkatan keterampilan guru mengembangkan pembelajaran dapat dilakukan melalui kegiatan pelatihan, seminar maupun lokakarya dengan memfungsikan kembali KKG atau kerjasama dengan perguruan tinggi penyelenggara pendidikan guru SD.

2. Bagi guru yang tidak berbakat dalam menggambar, agar dapat menuangkan konsep-konsep IPA pada KTSP untuk dituliskan dalam bentuk cerita, kemudian tuangkan dalam bentuk komik dengan cara mengunduh gambar dari internet.

3. Dalam pengaplikasian komik sebagai media pembelajaran perlu diperhatikan dalam penggunaan waktu saat proses pembelajaran berlangsung di ruang kelas.

\section{DAFTAR PUSTAKA}

Abidin, Y. (2009). Guru dan Pembelajaran Bermutu. Bandung: Rizqi Press

Badan Standarisasi Nasional Pendidikan. (2006). Pedoman Penyusunan Kurikulum Tingkat Satuan Pendidikan. Jakarta: Balitbang Depdiknas

Cameron, L. (2001). Teaching Languages to Young Learners. Cambridge: Cambridge University Press

Campbell, L. \& Dickinson, D. (1996). Teaching and Learning Through Multiple Intelligences. USA: Allyn and Bacon

Departemen Pendidikan Nasional. (2003). Undang-undang RI no. 20 tentang Sistem Pendidikan Nasional

E. Mol, S. et.al. (2009). Interactive Book Reading in Early Education: A Tool to Stimulate Print Knowledge as Well as Oral Language. Dalam Review of Educational Research [online], Vol 79, (2), pp. 979-1007. Tersedia: http://rer.sagepub.com/cgi/content/abstract/79/2/979 [9 Maret 2009]

Gega, P,C. (1982). Science In Elementary Education. New York : John Wiley and Sons 
Hammond, L, D. (2006). Powerful Teacher Education. San Fransisco: John Wiley \& Sons, Inc

Karli, H \& Yuliariatiningsih, M.S. (2004). Implementasi Kurikulum Berbasis Kompetensi Model-Model Belajar. Bandung : Bina Media Informasi

Muslim, A. (2009). Pengaruh Motivasi Belajar Terhadap Hasil Belajar IPA Siswa Kelas V Sekolah Dasar di Kecamatan Balubur Limbangan. Skripsi Universitas Pendidikan Indonesia: tidak diterbitkan

N' Namdi K. (2005). Guide to Teaching Reading at the Primary School Level. UNESCO

Nugraha, I,S,E. (2009). Penggunaan Media Komik untuk Meningkatkan Motivasi Belajar Siswa pada Pembelajaran IPA Konsep Pesawat Sederhana. Skripsi Universitas Pendidikan Indonesia: tidak diterbitkan

Pranata, M. (2003). Ceramah Desain Berbasis Keterampilan Visual. Jakarta : Gramedia

Prindani, W. (2009). Uji Coba Komik Fisika Berjudul Bunyi Karya Istianah Qudsi FT sebagai Media Pembelajaran IPA SMP Kelas VIII. Skripsi, Jurusan Pendidikan Fisika FMIPA Universitas Negeri Malang: tidak diterbitkan

Read, C. (2005). "Managing Children Positively”. Journal of English Teaching Professional. 38, 4-7.

Renner, J. W \& Stafford, Don. G. (1979). Teaching Science in in The Elementary School. New York : Harper \& Row Publishers

Sanjaya, W. (2007). Kajian Kurikulum dan Pembelajaran. Bandung: tidak diterbitkan

Sanjaya, W. (2008). Kurikulum dan Pembelajaran. Jakarta: Kencana Prenada Media Group

Santrock, J.W. (2008). Life Span Development. USA : Mc Graw Hill Inc

Smith, M, K. (2008). Howard Gardner and Multiple Intelligences, The Encyclopedia of Informal Education. [online]. http://.www.infed.org/thinkers/gardner.htm

Sumaji, et al. (1996). Pendidikan Sains yang Humanistis. Yogyakarta: Penerbit Kanisius

Tanner, R. (2001). “Teaching Intelligently”. Journal of English Teaching Professional. 20, 40-41.

Tanner, R \& Green. C (1998). Tasks for Teacher Education. New York: Longman

Tanpa nama (2008), Pengembangan Media Pembelajaran. [online] www.eduarticle.ahmadhidayat.blogspot.com

Tanpa nama (tanpa tahun). Theory of Multiple Intelligences. [online]. http://www.en.wikipedia.org/wiki/Theory_of_multiple_intelligences.htm

Yanthi, N. (2009). Pembelajaran IPA Secara Dwibahasa Melalui Metode Bercerita untuk Meningkatkan Multiple Intelligences Siswa SD Laboratorium UPI Kampus Cibiru. Jurnal Edu-Humaniora UPI Kampus Cibiru: UPI Press

Yuliariatiningsih, M, S. (2009). Model Direct Training untuk Meningkatkan Keterampilan Mahasiswa PGSD Cibiru Membelajarkan IPA SD dalam Bahasa Inggris. Jurnal Edu-Humaniora UPI Kampus Cibiru: UPI Press 
Wright, A. (2001). Art and Crafts with Children. Oxford: Oxford University Press

*) Margaretha Sri Yuliariatiningsih adalah dosen dan peneliti pada UPI Kampus Cibiru. 